\title{
Clinically stable very low birthweight infants are at risk for recurrent tissue glucose fluctuations even after fully established enteral nutrition
}

\author{
E Mola-Schenzle, ${ }^{1}$ A Staffler, ${ }^{2}$ M Klemme, ${ }^{1} \mathrm{~F}$ Pellegrini, ${ }^{2} \mathrm{G}$ Molinaro, ${ }^{2} \mathrm{~K}$ G Parhofer, ${ }^{3}$ \\ H Messner, ${ }^{2}$ A Schulze, ${ }^{1}$ A W Flemmer ${ }^{1}$
}

'Division of Neonatology, Dr von Hauner Children's Hospital and Perinatal Center, Ludwig Maximilian University Munich-Grosshadern, Munich, Germany

${ }^{2}$ Division of Neonatology, Regional Hospital Bolzano, Bolzano, Italy

${ }^{3}$ Department of Internal Medicine, Ludwig-MaximilianUniversity Munich-

Grosshadern, Munich, Germany

Correspondence to Dr Andreas W Flemmer, Department of Neonatology, Ludwig-Maximilians-University, Marchioninistreet 15, Munich, Bavaria 81377, Germany; andreas.flemmer@med.unimuenchen.de

Received 7 February 2014 Revised 7 October 2014 Accepted 20 October 2014 Published Online First 7 November 2014

\begin{abstract}
Objective In previous cases, we have observed occasional hypoglycaemic episodes in preterm infants after initial intensive care. In this prospective study, we determined the frequency and severity of abnormal tissue glucose (TG) in clinically stable preterm infants on full enteral nutrition.
\end{abstract}

Methods Preterm infants born at $<1000 \mathrm{~g}(\mathrm{n}=23 ; \mathrm{G} 1)$ and birth weight 1000-1500 $\mathrm{g}(\mathrm{n}=18 ; \mathrm{G} 2)$ were studied at a postmenstrual age of $32 \pm 2$ weeks (G1) and 33 \pm 2 weeks (G2). Infants were fed two or three hourly, according to a standard bolus-nutrition protocol, and continuous subcutaneous glucose measurements were performed for $72 \mathrm{~h}$. Normal glucose values were assumed at $\geq 2.5 \mathrm{mmol} / \mathrm{L}(45 \mathrm{mg} / \mathrm{dL})$ and $\leq 8.3 \mathrm{mmol} / \mathrm{L}$ $(150 \mathrm{mg} / \mathrm{dL})$. Frequency, severity and duration of glucose values beyond normal values were determined.

Results We observed asymptomatic low TG values in $39 \%$ of infants in G1 and in 44\% in G2. High TG values were detected in $83 \%$ in $\mathrm{G} 1$ and $61 \%$ in $\mathrm{G} 2$. Infants in $\mathrm{G} 1$ experienced prolonged and more severe low TG episodes, and also more frequent and severe high TG episodes. In G1 and G2, 87\% and $67 \%$ of the infants, respectively, showed glucose fluctuations characterised by rapid glucose increase followed by a rapid glucose drop after feeds. In more mature infants, glucose fluctuations were less pronounced and less dependent on enteral feeds.

Conclusions Clinically stable well-developing preterm infants beyond their initial period of intensive care show interstitial glucose instabilities exceeding values as low as $2.5 \mathrm{mmol} / \mathrm{L}$ and as high as $8.3 \mathrm{mmol} / \mathrm{L}$. This novel observation may play an important role for the susceptibility of these high-risk infants for the development of the metabolic syndrome.

Trial registration number German trial registration number DRKS00004590.

\section{INTRODUCTION}

Hypoglycaemic and hyperglycaemic events in the first hours, days and weeks of life are associated with risk factors, such as low gestational age (LGA), low birth weight, being born small for gestational age (SGA), and maternal conditions, like pregestational or gestational diabetes among other conditions both in the neonate and the mother.

Various authors described an incidence of hypoglycaemia and hyperglycaemia at different postnatal ages. Lubchenco and Bard ${ }^{1}$ reported hypoglycaemia $(<1.7 \mathrm{mmol} / \mathrm{L})$ in $15 \%$ of preterm infants who were appropriate for gestational age and in

\section{What is already known on this topic}

- Preterm infants are at risk for postnatal metabolic instability.

- Instabilities occur during immediate postnatal intensive care while on parenteral nutrition.

- Both high and low glucose levels are associated with poor outcome.

\section{What this study adds}

- This is the first prospective study showing that metabolic instabilities still occur in very low birthweight infants at a median-corrected gestational age of $324 / 7$ or 37 days of life.

- Metabolic instability remains, especially in extremely low gestational age infants while already clinically stable and already on full enteral nutrition.

- Continuous tissue glucose monitoring is able to identify infants at risk for metabolic instabilities at a median-corrected gestational age of $324 / 7$ or 37 days of life.

$67 \%$ of infants who were SGA during their first $6 \mathrm{~h}$ of life. Alexandrou et $a l^{2}$ diagnosed hypoglycaemia $(<2.6 \mathrm{mmol} / \mathrm{L})$ in $41 \%$ and hyperglycaemia $(>8.3 \mathrm{mmol} / \mathrm{L})$ in $81 \%$ of preterm infants during the first week of life and reported an association of hyperglycaemia with death and white matter reduction. Lucas $e t a l^{3}$ described hypoglycaemic events $(<2.6 \mathrm{mmol} / \mathrm{L})$ in $39 \%$ of infants with birth weight $<1000 \mathrm{~g}$ in the first month, which in $10 \%$ were still detected after the fourth week of life.

Previous studies were based on repeated capillary, arterial or venous glucose measurements, and usually glucose measurements are frequently performed during the first days of life, successively reduced and, therefore, only rarely performed once the infants have reached full enteral nutrition.

In a previous chart analyses, we detected occasional hypoglycaemic episodes in clinically stable formerly preterm infants fed on a standard bolusfeed protocol with both enriched breast milk as well as preterm formula. ${ }^{4}$ Based on these observations, we hypothesised that clinically stable very low birthweight (VLBW) preterm infants are still 
susceptible to developing asymptomatic fluctuations of glucose levels once on full enteral nutrition. In this prospective study, we aimed to determine the frequency and severity of tissue glucose (TG) fluctuations in VLBW infants after having reached full enteral feeds over a $72 \mathrm{~h}$ period using a continuous glucose monitoring system (CGMS).

\section{PATIENTS AND METHODS}

We conducted a prospective observational cohort study (German trial registration number DRKS00004590) with continuous subcutaneous glucose monitoring of preterm infants at the Division of Neonatology, Perinatal Center, LM-University Munich, Germany, Campus Grosshadern, and at the Neonatology Department of the Regional Hospital in Bolzano, Italy. The institutional ethical committees in both hospitals approved the study, and parental informed consent was obtained prior to enrolment. Patients were recruited between April 2011 and February 2013 in both centres. Inclusion criteria were (1) birth weight $<1500 \mathrm{~g}$, (2) gestational age $<32$ weeks postmenstrual age, (3) on full enteral feeds for at least 5 days and (4) otherwise clinically stable (no invasive respiratory support, no signs of infection, no severe desaturation- $\mathrm{SpO}_{2}<80 \%-$ and bradycardia heart rate $<80 / \mathrm{min}$ ). Exclusion criteria were (1) a pathological neonatal metabolic screening test on the third day of life (DOL) (routine testing in newborns to screen for certain genetic, metabolic and endocrine disorders), (2) a positive family history for metabolic diseases, (3) major congenital malformations and (4) any acute illness requiring intensive care intervention.

Infants were stratified into two groups according to birth weight: <1000 g $(\mathrm{G} 1, \mathrm{n}=23)$ and $1000 \mathrm{~g}-1500 \mathrm{~g}(\mathrm{G} 2, \mathrm{n}=18)$, as we have previously observed occasional low blood glucose values in formerly preterm infants especially in infants born at $<1000$ g. ${ }^{4}$ Infants at extremes of their gestational age-related birth weight (SGA, LGA) are at increased risk for glucose instabilities. $^{1}$ 5-7 Thus, we decided to stratify infants by birth weight rather than gestational age at birth.

Subcutaneous TG was measured continuously over $72 \mathrm{~h}$ with a standard CGMS (CGMS; Guardian REAL-time, Soft sensor, Medtronic GmbH, Meerbusch, Germany). The sensor tip was manually inserted under sterile conditions through the intact skin in the subcutaneous tissue of the infant's thigh. It has a platinum electrode that catalyses interstitial glucose oxidation and determines average values every $5 \mathrm{~min}$. Results are transferred wirelessly to a receiver displaying them in real time.

Intermittently, capillary blood samples were analysed with a 'point of care' (POC) blood gas analyser (Amperometric glucose measurement, Radiometer, ABL 700, Copenhagen, Denmark), to calibrate the subcutaneous sensor. The POC device is regularly quality insurance tested for three ranges of values: (1) glucose values $<2.5 \mathrm{mmol} / \mathrm{L}$ (median $1.6 \mathrm{mmol} / \mathrm{L}$, CI 1.44 to $1.66 \mathrm{mmol} /$ L), (2) glucose values $<6.6 \mathrm{mmol} / \mathrm{L}$ (median $5.7 \mathrm{mmol} / \mathrm{L}$, CI 5.40 to $5.58 \mathrm{mmol} / \mathrm{L}$ ), (3) glucose values $>13.9 \mathrm{mmol} / \mathrm{L}$ (median $14.2 \mathrm{mmol} / \mathrm{L}$, CI 12.13 to $14.95 \mathrm{mmol} / \mathrm{L}$ ).

These blood glucose readings were compared with the values obtained by the CGMS in order to assess the accuracy of the device. In order to evaluate the accuracy of the CGMS method, we calculated the correlation between paired glucose readings from capillary blood samples measured with a POC blood gas analyser and the corresponding CGMS interstitial glucose values $\left(\mathrm{R}^{2}=0.57, \mathrm{p}<0.001 ; \mathrm{n}=307\right.$; Pearson's correlation coefficient; Wilcoxon Signed Rank test). On BlandAltman analysis, the mean difference between both monitoring systems was $-0.011 \mathrm{mmol} / \mathrm{L}$ (95\% CI -0.13 to 0.11 , IQR $4.5-$ $6.1 \mathrm{mmol} / \mathrm{L}$; figure 1). The use of the CGMS has previously been validated to detect periods of hyperglycaemia and hypoglycaemia in preterm infants and in term infants at risk of glucose fluctuations. ${ }^{8-10}$ Unfortunately, normal values of CGM in the neonatal period of healthy term infants are not available. During the whole study, we did not detect any adverse effect of CGM in preterm infants, especially, no local or systemic infection associated with the application of the sensor was observed.

All infants were fed according to a standard bolus-feeding protocol where full enteral nutrition was provided at $150-180 \mathrm{~mL} / \mathrm{kg} /$ day with fortified breast milk or preterm formula at $110-135 \mathrm{kcal} / \mathrm{kg} /$ day two, three or four hourly depending on the age, and the tolerance of the intakes. The feeding protocol was according to the recommendations of the European Society for Paediatric Gastroenterology, Hepatology and Nutrition Committee on Nutrition for preterm infants. ${ }^{11}$

Despite the fact that the plasma glucose concentrations that define low and high glucose values in newborns are without rigorous scientific justification, ${ }^{12-15} 16$ we adopted thresholds for low TG values $(\leq 2.5 \mathrm{mmol} / \mathrm{L} ; \leq 45 \mathrm{mg} / \mathrm{dL})$ and high TG values by two cut-off levels, $(>8.3 \mathrm{mmol} / \mathrm{L} ;>150 \mathrm{mg} / \mathrm{dL}$ and
Figure 1 Bland-Altman Plot, continuous glucose monitoring system (CGMS) versus point of care (ABL). Horizontal axis represents the mean of the sensor (CGMS) and point-of-care glucose measurement (mmol/L). Vertical axis represents the difference between the sensor (CGMS) and the point-of-care glucose measure $(\mathrm{mmol} / \mathrm{L})$. Solid lines indicate \pm 2 SD.

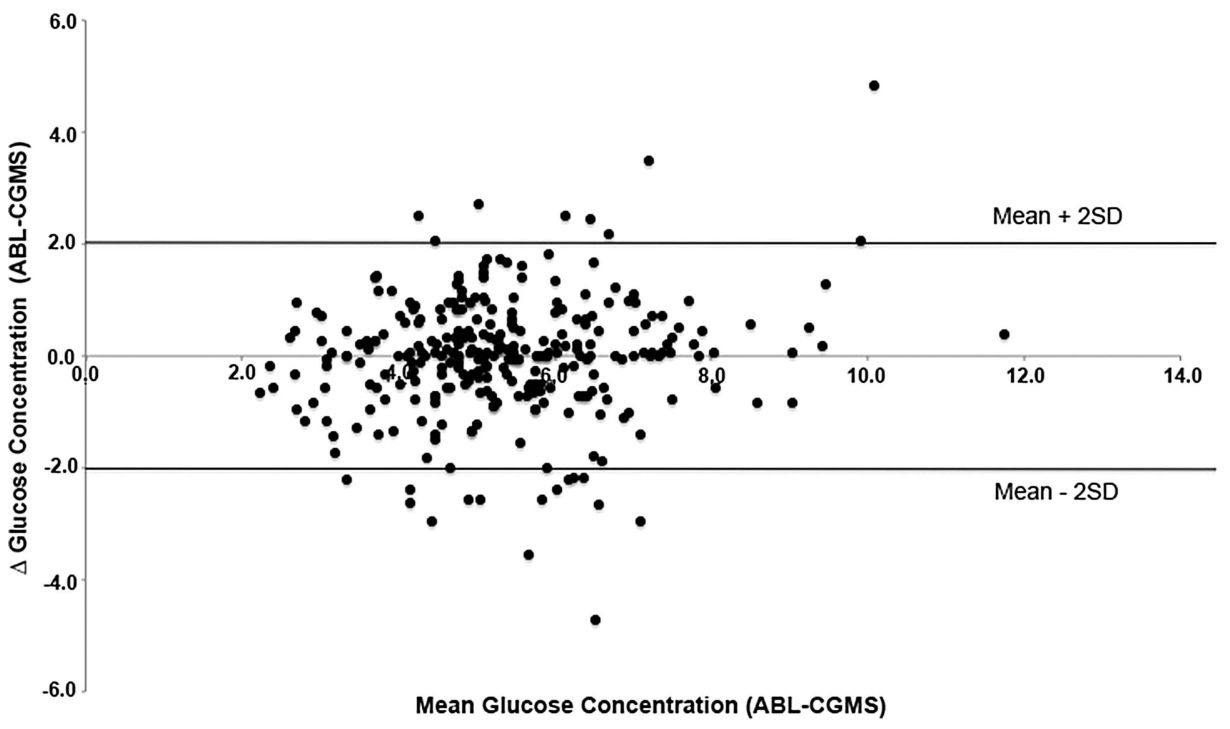




\section{Original article}

$>11.1 \mathrm{mmol} / \mathrm{L} ;>200 \mathrm{mg} / \mathrm{dL}$ ) in accordance with previous studies on blood glucose..$^{17-19}$

The variability of TG was calculated as the SD of TG values per infant throughout the study period (TG-SD). ${ }^{20}{ }^{21}$ In order to identify possible risk factors associated with high-amplitude TG fluctuations, we correlated individual SD values with potential risk factors for glucose instability: gestational age at birth and at trial entry, nutritional components like total fluids, carbohydrates, protein and lipids, as well as total days on parenteral nutrition prior to CGM. Additionally, the Clinical Risk Index for Babies (CRIB-Score) and the Body Mass Index (BMI) at birth were calculated and evaluated. The CRIB score is a composite score for preterm infants born at $<1500 \mathrm{~g}$, derived from birth weight, gestational age, lowest base excess, minimal and maximal $\mathrm{FiO} 2$ within the first $12 \mathrm{~h}$ of life and malformations. Thus, a high CRIB-score is an indicator for poor outcome. ${ }^{22}$

Data were analysed using the Statistical Package for Social Sciences V.20.0 (SPSS, Chicago, Illinois, USA).

Statistical analysis within cohorts was carried out with $\chi^{2}$ tests to rule out any effect of confounding factors. For the calculation of significance levels across cohorts, non-parametric MannWhitney U test or a Kruskal Wallis test was used. Since many of the variables were not distributed normally, the median and IQRs for both cohorts were calculated and are the main measures reported. Risk factors were correlated to TG-SD by Pearson's correlation. Further analysis of these factors was achieved by stepwise linear regression analysis. The level of significance was set at $\mathrm{p}<0.05$.

\section{RESULTS}

Table 1 displays demographics and characteristics of infants enrolled in both strata at birth and at trial entry. The infants in both groups were enrolled at a median-corrected postmenstrual age of 37 DOL (IQR: 31 DOL-48 DOL) and a mediancorrected gestational age of 33 weeks (IQR: 31 3/7-34 3/7).

TG values obtained with the CGMS showed cyclic fluctuations exceeding $2.5 \mathrm{mmol} / \mathrm{L}$ and $8.3 \mathrm{mmol} / \mathrm{L}$ throughout the day. Typically, high TG peaks were followed by rapid drops concomitant with the feeding schedule. These fluctuations occurred regardless of whether the infant was fed two, three or four hourly. By contrast, TG fluctuations were less pronounced and remained within the predefined range in G2, despite the fact that both groups were approximately 33 weeks corrected postmenstrual age at trial entry (median-IQR: 31 3/7-34 3/7). The majority of infants $(75 \%)$ were fed three hourly. In figure 2 , the combined measurements of all these infants is outlined as mean $\pm 2 \mathrm{SDs}$, with the grey area indicating the presumed normal range of $2.5-8.3 \mathrm{mmol} / \mathrm{L}$ (figure 2 ).

TG values fluctuated beyond the predefined limits in $20 / 23$ $(87 \%)$ infants in G1 and 12/18 (67\%) infants in G2. Only nine of the 41 enrolled infants $(22 \%, 3 / 23$ in G1 and 6/18 in G2) had stable TG values within the normal range throughout the entire study period (table 2 ).

Of all infants, $12 \%$ showed at least one episode of low TG, $37 \%$ had at least one episode of high TG and 29\% suffered both low and high TG throughout the monitored time. The occurrence of low TG was similar in both groups (39\% in G1 and $44 \%$ in G2), whereas high TG was more frequent in G1 (83\%) compared with G2 (61\%, table 2).

In $\mathrm{G} 1,1 / 23(4 \%)$ infants had very low TG $(<1.7 \mathrm{mmol} / \mathrm{L} /$ $31 \mathrm{mg} / \mathrm{dL}$ ) and $8 / 23(35 \%)$ values between 1.7 and $2.5 \mathrm{mmol} / \mathrm{L}$ (31-45 mg/dL). In G2, 8/18 (44\%) presented TG values $<2.5 \mathrm{mmol} / \mathrm{L}(<45 \mathrm{mg} / \mathrm{dL})$, whereas no infant developed values below $1.7 \mathrm{mmol} / \mathrm{L}(31 \mathrm{mg} / \mathrm{dL})$. Considering the high TG threshold $>8.3 \mathrm{mmol} / \mathrm{L}(150 \mathrm{mg} / \mathrm{dL}), 8 / 23(35 \%)$ in $\mathrm{G} 1$ and $9 / 18$ $(50 \%)$ in G2 developed recurrent high TG episodes. A TG value above $11.1 \mathrm{mmol} / \mathrm{L}(200 \mathrm{mg} / \mathrm{dL})$ was observed in $11 / 23(48 \%)$ infants in G1 and 2/18 (11\%) in G2 (table 2 and figure 3A-C). Figure $3 \mathrm{C}$ illustrates the duration and severity of all 402 recorded low and high TG episodes.

Of the registered 38 episodes of low TG values among all infants, $12 / 38 \quad(32 \%)$ lasted $<10 \mathrm{~min}, 12 / 38 \quad(32 \%)$ lasted 10-30 min, 9/38 (24\%) lasted 30-60 min and 5/38 (13\%) lasted $>60 \mathrm{~min}$. Seventeen patients had hypoglycaemic episodes during the $72 \mathrm{~h}$ monitoring. Of these 17 patients, 10 (59\%) had only one hypoglycaemic episode and seven $(41 \%)$ had more than one hypoglycaemic episodes. Of the infants with recurrent hypoglycaemic episodes, four were in G1 and three belonged in G2.

Table 1 Infants' characteristics (median-IQRs)

\begin{tabular}{|c|c|c|}
\hline & $\mathrm{BW}<1000 \mathrm{~g}$ & BW $1000-1500 \mathrm{~g}$ \\
\hline \multicolumn{3}{|l|}{ Baseline } \\
\hline Number & 23 & 18 \\
\hline Gestational age (weeks) & $255 / 7(241 / 7-27)$ & $296 / 7(28$ 5/7-30 3/7) \\
\hline Birth weight (g) & $672.5(615-900)$ & $1210.0(1152.5-1327.5)$ \\
\hline BMI & $6.8(6.3-7.3)$ & $7.7(7.1-8.4)$ \\
\hline SGA (\%) & 17 & 11 \\
\hline Male (\%) & 65 & 72 \\
\hline Antenatal glucocorticoids (\%) & 91 & 100 \\
\hline Caesarean section (\%) & 87 & 89 \\
\hline CRIB score & $7(2-8)$ & $1(1-1.25)$ \\
\hline \multicolumn{3}{|l|}{ At study entry } \\
\hline Day of life & $47.0(38-53)$ & $31.0(26-36)$ \\
\hline Gestational age (weeks) & 32 2/7 (30 4/7-33 5/7) & 33 5/7 (32 5/7-34 6/7) \\
\hline Weight (g) & $1350.0(1246.25-1510)$ & $1650.0(1570-1805)$ \\
\hline Length $(\mathrm{cm})$ & $39.0(36.0-41.0)$ & $41.8(41-42.6)$ \\
\hline Head circumference $(\mathrm{cm})$ & $27.0(25.5-29.0)$ & $28.8(28.0-29.9)$ \\
\hline Total length of parenteral nutrition (days) & $17(12-23)$ & $12(9-13)$ \\
\hline Days after end of total parenteral nutrition & $28(18-43)$ & $19(15-23)$ \\
\hline
\end{tabular}


Figure 2 Cumulated tissue glucose (TG) tracings from all infants on 3-hourly bolus feeds (eight feedings per day, $\mathrm{n}=31$ ). Black line indicates mean tissue glucose within $24 \mathrm{~h}$; grey lines indicate 2SD TG values indicating mealassociated fluctuations. Grey area outlines the normal range $>2.5 \mathrm{mmol} / \mathrm{L}-\leq 8.3 \mathrm{mmol} / \mathrm{L}$.

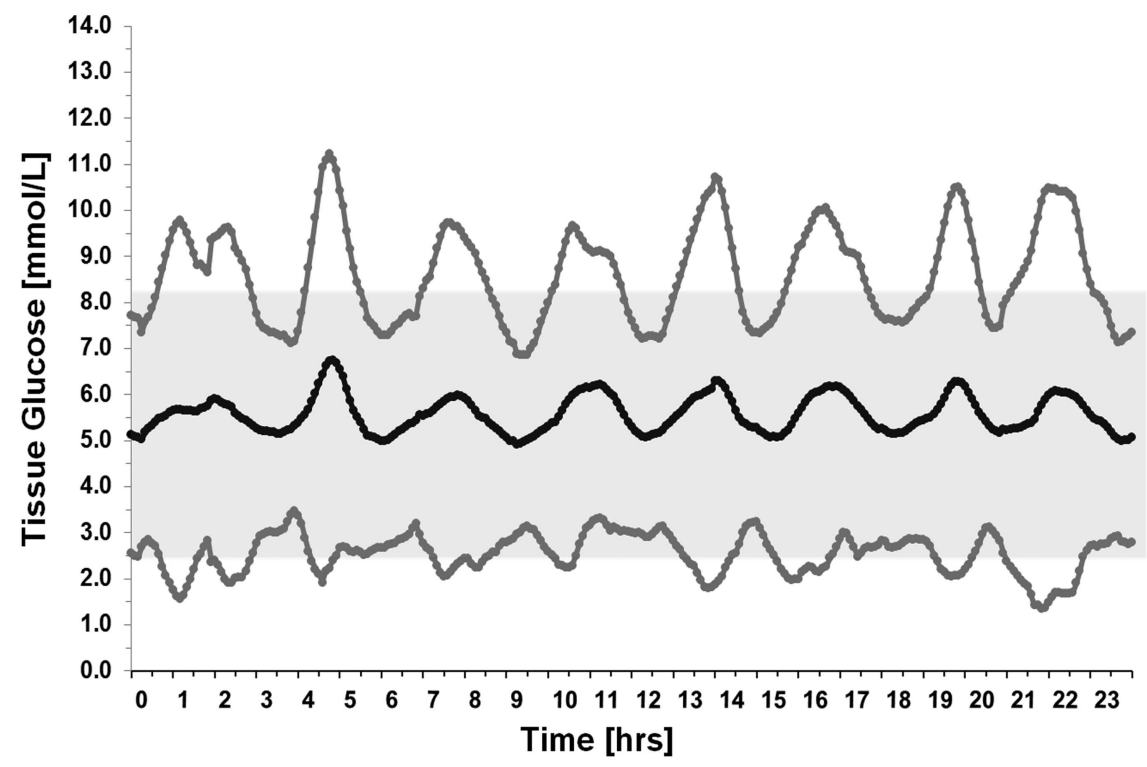

A total of 305 episodes with high glucose values between 8.3 and $11.1 \mathrm{mmol} / \mathrm{L}$ were recorded. Of those, 13 (4\%) lasted $<10 \mathrm{~min}, 174(57 \%)$ lasted 10-30 min, 67 (22\%) lasted 30-60 $\min$ and $51(17 \%)$ lasted $>60 \mathrm{~min}$. Of the 59 episodes of severe high TG episodes ( $>11.1 \mathrm{mmol} / \mathrm{L}), 2$ (3\%) lasted $<10 \mathrm{~min}, 32$ (54\%) between $10 \mathrm{~min}$ and $30 \mathrm{~min}, 12(38 \%)$ lasted 30-60 min and $13(22 \%)$ lasted $>60$ min (figure 3D).

TG-SDs were negatively correlated with the gestational age at birth $(\mathrm{R}=-0.43 ; 95 \% \mathrm{CI}-0.64$ to -0.06$)$, the gestational age at study entry $(\mathrm{R}=-0.42 ; 95 \% \mathrm{CI}-0.64$ to -0.15$)$, the BMI at birth $(\mathrm{R}=-0.32 ; 95 \% \mathrm{CI}-0.53$ to -0.06$)$, and positively correlated with the total days on parenteral nutrition $(\mathrm{R}=0.56 ; 95 \%$ CI 0.21 to 0.74$)$, as well as the CRIB-score at birth $(\mathrm{R}=0.43$; $95 \%$ CI 0.11 to 0.61 ). In the linear regression model, only the number of days on total parenteral nutrition remained a significant risk factor for TG fluctuations $(p=0.02)$ and the gestational age at study entry just missed significance $(p=0.07)$. Nutritional components, total fluids and BMI at birth had no effect on TG-SD. TG variability was not related to gender, mode of delivery, bronchopulmonary dysplasia, IVH (intraventricular haemorrhage) and periventricular leukomalacia. We could not detect any significant difference in weight gain 7 days before and after the monitoring period, either among cohorts or when trying to relate them to low or high glucose events. However, the nine infants in this study (3/23 in G1 and 6/18 in G2) with glucose

\begin{tabular}{lll} 
Table 2 Results & & \\
\hline & BW $<1000 \mathrm{~g}$ & BW 1000-1500 g \\
\hline Number & 23 & 18 \\
Infants with tissue glucose fluctuations & $87 \%(20)$ & $67 \%(12)$ \\
Stable infants & $13 \%(3)$ & $33 \%(6)$ \\
Incidence of low tissue glucose values & $39 \%$ & $44 \%$ \\
Tissue glucose values $<1.7 \mathrm{mmol} / \mathrm{L}$ & $4 \%(1)$ & - \\
Tissue glucose values $1.7-2.5 \mathrm{mmol} / \mathrm{L}$ & $35 \%(8)$ & $44 \%(8)$ \\
Incidence of high tissue glucose values & $83 \%$ & $61 \%$ \\
Tissue glucose values $>8.3 \mathrm{mmol} / \mathrm{L}$ & $35 \%(8)$ & $50 \%(9)$ \\
Tissue glucose values $>11.1 \mathrm{mmol} / \mathrm{L}$ & $48 \%(11)$ & $11 \%(2)$ \\
\hline BW, birth weight. & &
\end{tabular}

values within the predefined glucose range of $2.5-8.3 \mathrm{mmol} / \mathrm{L}$ showed a significantly better weight gain than unstable ones $(p=0.046)$.

\section{DISCUSSION}

In this study, we report for the first time glucose instabilities in preterm infants after their initial postnatal period of intensive care. The infants in our study were clinically stable on full enteral bolus nutrition without any potential reason for glucose fluctuations beyond normal limits. In general, clinically stable preterm infants are assumed to be also metabolically stable as soon as blood glucose measurements have repeatedly returned values within a normal range. As a result, further blood glucose measurements are normally not routinely performed. ${ }^{18} 23$ To date, we are not able to conclude whether our novel findings on TG are worrisome, because there are no normal TG values available for preterm infants. However, several authors reported that repeated episodes of hypoglycaemia with values $<2.6 \mathrm{mmol} / \mathrm{L}$ in the early postnatal period, both symptomatic and asymptomatic, impair neurodevelopment. ${ }^{3}$ 24-26 Hypoglycaemia is associated with reduced brain growth and neonatal brain injury. ${ }^{24} 27-29$ Additionally, hyperglycaemia in the first week of life has been described as a risk factor associated with death, severe IVH and white matter reduction. ${ }^{2} 19$

Alexandrou et $a l^{2}$ reported that only 10 of 113 infants born at $<27$ weeks gestational age maintained a normoglycemic level in the first week of life. We performed glucose measurements between the third and eighth week of life and registered 38 episodes of low glucose episodes, 305 of moderately high glucose episodes (>8.3 mmol/L-150 mg/dL) and 59 events of severely elevated levels with TG levels $>11.3 \mathrm{mmol} / \mathrm{L} / 200 \mathrm{mg} / \mathrm{dL}$. After the first 10 DOL, frequent glucose measurements are not considered to be needed in clinically stable infants without risk factors, especially after reaching full enteral feeds. ${ }^{12} 30$ The high incidence of high and low glucose levels detected in this study by CGMS demonstrates for the first time that this assumption does not hold true for former VLBW infants. These prospective data confirm our previous retrospective chart analysis. ${ }^{4}$ For VLBW infants, the difficulty to maintain their systemic glucose level within a normal range seems to continue even after the first month of life, despite clinical stability and full enteral nutrition according to current nutritional guidelines. ${ }^{11}$ 

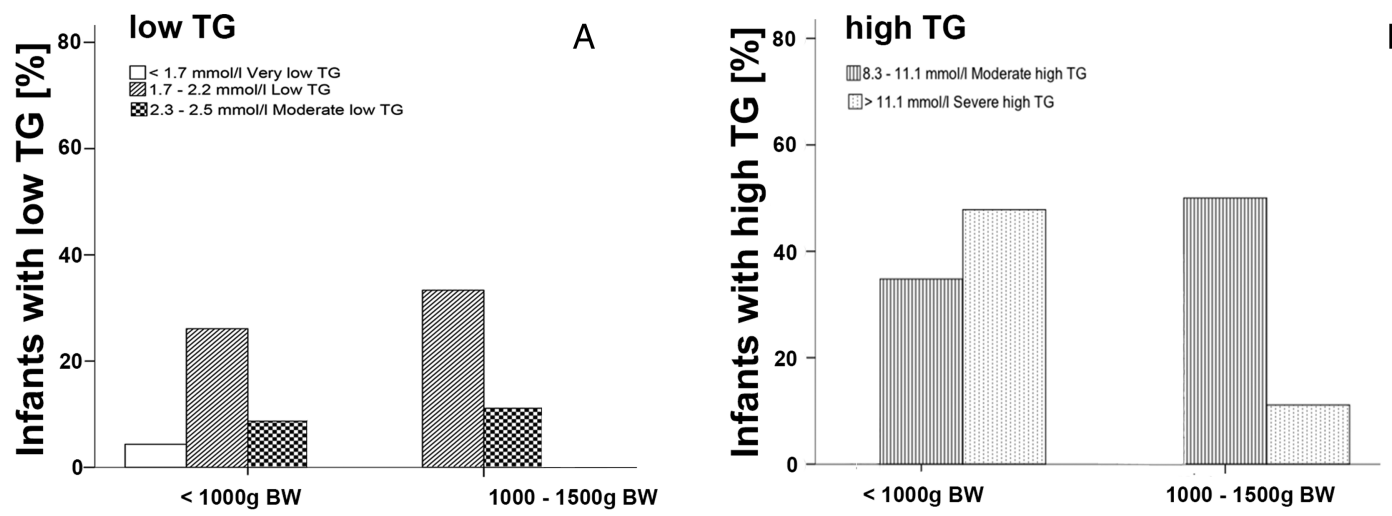

B
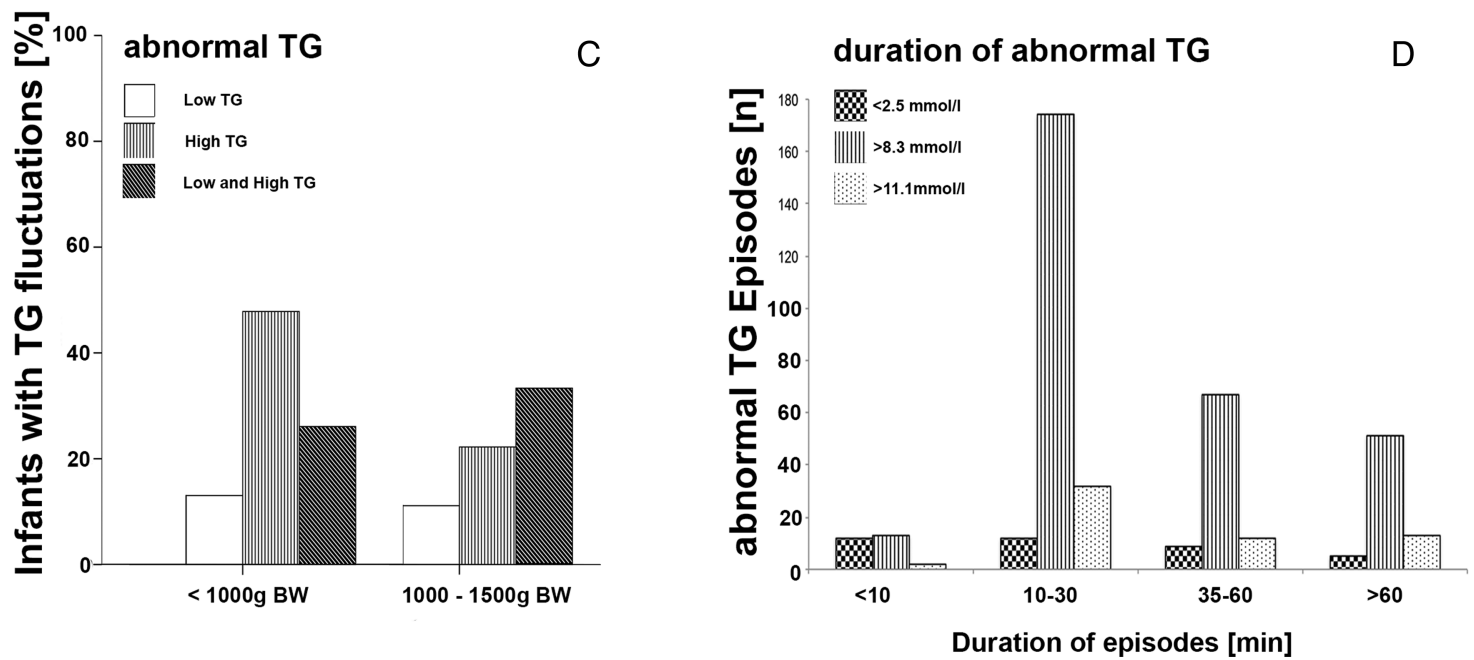

Figure 3 (A-D) Frequency (\% of infants in cohort) of low (A) and high (B) tissue glucose (TG) episodes with regard to severity in both weight cohorts. (C) Overall frequency (\% of infants in cohort) of abnormal TG. (D) Duration and severity of all recorded episodes.

All the 402 registered low and high glucose episodes in this study were asymptomatic. This finding is of major concern, as both extremes have been demonstrated previously to potentially harm these infants. ${ }^{3} 2122242527$

By using CGMS, we were able to assess the duration of glucose values beyond the normal range. Almost one quarter of the low glucose episodes lasted between 30 and $60 \mathrm{~min}$, whereas the more frequent high glucose episodes lasted usually between 10 and $30 \mathrm{~min}$, and in $17 \%>60 \mathrm{~min}$. It is quite worrying that VLBW infants show high glucose levels at this age, since the same glucose values in the first week of life are associated with increased mortality and white matter reduction. ${ }^{2}$ Additionally, we registered episodes of high TG, of which 54\% lasted 10$30 \mathrm{~min}, 20 \%$ between 30 and $60 \mathrm{~min}$ and 22\% longer than $60 \mathrm{~min}$. Several follow-up studies have shown that previously preterm infants are at risk for intima thickening of vessels and for the development of metabolic syndrome later in life. ${ }^{31-33}$ Our data might provide the link between these findings and the cause of future sequelae of extremely preterm infants as we find especially high prevalence of high TG in these infants.

A weakness of our study is the low sample size. Nevertheless, the variability of TG (TG-SD) in our two cohorts decreases with increased gestational age at birth, a higher BMI at birth as well as with increased postmenstrual age at the time of measurements. And the duration of parenteral nutrition, typically shorter in more mature infants, remained significant in the linear regression model.

Despite not reaching significance in the regression model, all our data point to prematurity per se being the major risk factor for glucose instabilities after birth. It has been shown in the past that metabolic adaptation in preterm infants differs from infants born at term. Immature neonates (24-29 weeks gestational age and birth weight between 600 and $1200 \mathrm{~g}$ ) can produce glucose via glycogenolysis and gluconeogenesis at rates comparable with term newborns during their first DOL, but the functional immaturity of the enzymatic systems increases the propensity to hypoglycaemic episodes. ${ }^{18} 3435$ During the first postnatal week, the relation between glucose and other energy sources in preterm infants are low because they cannot sustain gluconeogenesis at the same rate as term newborns. The accumulation of glycogen, fat and protein occurs only in the last 8 weeks of pregnancy, and since VLBW infants are born substantially earlier, they are not able to tolerate long periods of fasting. ${ }^{18} 34$ Blood glucose values have been shown to vary more in preterm infants after birth. On one hand, the immaturity of the glucose sensor in the pancreatic $\beta$ cell leads to an inability to downregulate insulin secretion during hypoglycaemia. On the other hand, the hepatocyte response to the circulating insulin concentrations during hyperglycaemia is immature as well, instead continuing with their glucose production. ${ }^{17}$

The relative lack of adipose tissue $(<2 \%$ of total body weight) and glycogen stores in this group of neonates results in an incapability of producing alternative fuels to maintain euglycaemia via glycogenolysis and gluconeogenesis for long periods of fast, causing a limitation for protective metabolic counterregulation during hypoglycaemia. ${ }^{18}$ In preterm infants, the endocrine and enzyme control of intermediate metabolism is 
immature and not fully developed, leading to a failed homeostasis. They are less able than term infants to adapt to cessation of intrauterine nutrition, and they depend partly on total parental nutrition during the first weeks of life. ${ }^{17} 343637$

Preterm infants also have lower ketone body concentrations, even at lower glucose values, than term infants. ${ }^{36}$ Glucose-regulated insulin secretion (first detected at the 11th week of gestation, but not released until the 20th week) by the pancreatic $\beta$ cell is still immature in preterm infants, resulting in unregulated and inadequate insulin production and secretion. The plasma insulin concentration and the insulin/glucose ratio increase exponentially with gestation, indicating the maturation of the pancreas. ${ }^{18}{ }^{35}$ In our study, insulin secretion was not determined due to ethical reasons. TG values determined by CGM measurements very well represent blood glucose values even in preterm infants. ${ }^{38}$ However, TG values change mirror glucose values with a substantial time delay of about $20 \mathrm{~min}$. Thus, repeated blood samples would have been necessary to actually determine corresponding blood insulin levels. However, we speculate that immature glucose metabolism at the time of our measurements is responsible for glucose derailments detected in this study. The preterm organism is, most likely, not yet equipped to deal with repeated high caloric bolus nutrition, a usual practice in neonatal intensive care units today. ${ }^{18} 233637$ Current feeding practices for preterm neonates involve small bolus meals, for example, every $2-4 \mathrm{~h}$.

\section{CONCLUSION}

The incidence of low and high glucose episodes without any clinical signs in stable, fully enteral-fed preterm infants is high. This is the first study to describe glucose instability in these infants, and prematurity may be a key factor for this phenomenon. Whether breast milk fortification is responsible and whether persisting glucose fluctuations in preterm infants have a long-term effect with regard to somatic and neurological development in these infants require further studies.

Acknowledgements Vincent Gaertner is acknowledged for the statistical review of the manuscript.

Contributors EM-S and AS contributed equally to the study design, data collection and statistical analysis, and in writing and editing the manuscript, and approved the final version of the manuscript. MK, FP and GM were responsible for data collection, evaluation, drafting the work and in editing the manuscript, and approved the final manuscript as submitted. AS, HM and KGP contributed to study design and data interpretation and critically revised the manuscript, and approved the final version of the manuscript. AWF was responsible for study design, patient acquisition, data acquisition, manuscript writing and editing and approved the final manuscript as submitted.

Funding This study was funded by institutional funding.

Competing interests None.

Ethics approval Ethical committee of the Medical Faculty, Ludwig Maximilians University Munich, Germany.

Provenance and peer review Not commissioned; externally peer reviewed.

\section{REFERENCES}

1 Lubchenco LO, Bard $\mathrm{H}$. Incidence of hypoglycemia in newborn infants classified by birth weight and gestational age. Pediatrics 1971;47:831-8.

2 Alexandrou G, Skiold B, Karlen J, et al. Early hyperglycemia is a risk factor for death and white matter reduction in preterm infants. Pediatrics 2010;125:e584-91.

3 Lucas A, Morley R, Cole TJ. Adverse neurodevelopmental outcome of moderate neonatal hypoglycaemia. BMJ 1988;297:1304-8.

4 Staffler A, Klemme M, Mola-Schenzle E, et al. W. Very low birth weight preterm infants are at risk for hypoglycemia once on total enteral nutrition. J Matern-Fetal Neonatal Med 2013;26:1337-41.

5 Beardsall K, Diderholm BM, Dunger DB. Insulin and carbohydrate metabolism. Best Pract Res Clin Endocrinol Metab 2008:22:41-55.
6 Hawdon JM, Ward Platt MP. Metabolic adaptation in small for gestational age infants. Arch Dis Child 1993;68(3 Spec No):262-8.

7 Holtrop PC. The frequency of hypoglycemia in full-term large and small for gestational age newborns. Am J Perinatol 1993;10:150-4.

8 Harris DL, Battin MR, Weston PJ, et al. Continuous glucose monitoring in newborn babies at risk of hypoglycemia. J Pediatr 2010;157:198-202 e1.

9 Beardsall K, Ogilvy-Stuart AL, Ahluwalia J, et al. The continuous glucose monitoring sensor in neonatal intensive care. Arch Dis Child Fetal Neonatal Ed 2005;90: F307-10.

10 Beardsall K, Vanhaesebrouck S, Ogilvy-Stuart AL, et al. Validation of the continuous glucose monitoring sensor in preterm infants. Arch Dis Child Fetal Neonatal Ed 2013:98:F136-40.

11 Agostoni C, Buonocore G, Carnielli VP, et al. Enteral nutrient supply for preterm infants: commentary from the European Society of Paediatric Gastroenterology, Hepatology and Nutrition Committee on Nutrition. J Pediatr Gastroenterol Nutr 2010;50:85-91.

12 Adamkin DH. Postnatal glucose homeostasis in late-preterm and term infants. Pediatrics 2011;127:575-9.

13 Srinivasan G, Pildes RS, Cattamanchi G, et al. Plasma glucose values in normal neonates: a new look. J Pediatr 1986;109:114-17.

14 Koh TH, Eyre JA, Aynsley-Green A. Neonatal hypoglycaemia-the controversy regarding definition. Arch Dis Child 1988;63:1386-8.

15 Hay WW. Addressing hypoglycemia and hyperglycemia. Pediatr Rev 1999;20:4e-5.

16 Cornblath M, Hawdon JM, Williams AF, et al. Controversies regarding definition of neonatal hypoglycemia: suggested operational thresholds. Pediatrics 2000;105:1141-5.

17 Hemachandra AH, Cowett RM. Neonatal Hyperglycemia. Pediatr Rev 1999;20:e $16-24$.

18 Farrag HM, Cowett RM. Glucose homeostasis in the micropremie. Clin Perinatol 2000;27:1-22, v.

19 Hays SP, Smith EO, Sunehag AL. Hyperglycemia is a risk factor for early death and morbidity in extremely low birth-weight infants. Pediatrics 2006;118:1811-18.

20 Fendler W, Walenciak J, Mlynarski W, et al. Higher glycemic variability in very low birth weight newborns is associated with greater early neonatal mortality. J Matern Fetal Neonatal Med 2012;25:1122-6.

21 Wintergerst KA, Buckingham B, Gandrud L, et al. Association of hypoglycemia, hyperglycemia, and glucose variability with morbidity and death in the pediatric intensive care unit. Pediatrics 2006;118:173-9.

22 Rautonen J, Makela A, Boyd H, et al. CRIB and SNAP: assessing the risk of death for preterm neonates. Lancet 1994;343:1272-3.

23 Platt MP, Hawdon JM. Hypoglycaemia in the neonate. Baillieres Clin Endocrinol Metab 1993;7:669-82.

24 Duvanel $\mathrm{CB}$, Fawer $\mathrm{CL}$, Cotting J, et al. Long-term effects of neonatal hypoglycemia on brain growth and psychomotor development in small-for-gestational-age preterm infants. The Journal of pediatrics 1999;134:492-8.

25 Koh TH, Aynsley-Green A, Tarbit M, et al. Neural dysfunction during hypoglycaemia. Arch Dis Child 1988;63:1353-8.

26 Hawdon JM. Hypoglycaemia and the neonatal brain. Eur J Pediatr 1999;158(Suppl 1):S9-12.

27 Salhab WA. Initial Hypoglycemia and Neonatal Brain Injury in Term Infants With Severe Fetal Acidemia. Pediatrics 2004;114:361-66.

28 Burns CM, Rutherford MA, Boardman JP, et al. Patterns of cerebral injury and neurodevelopmental outcomes after symptomatic neonatal hypoglycemia. Pediatrics 2008;122:65-74.

29 Tam EW, Widjaja E, Blaser SI, et al. Occipital lobe injury and cortical visual outcomes after neonatal hypoglycemia. Pediatrics 2008;122:507-12

30 Society CP. Screening guidelines for newborns at risk for low blood glucose. Paediatr Child Health 2004;9:723-9.

31 Schubert $\mathrm{U}$, Muller $\mathrm{M}$, Abdul-Khaliq $\mathrm{H}$, et al. Relative intima-media thickening after preterm birth. Acta Paediatr 2013;102:965-9.

32 Parkinson JR, Hyde MJ, Gale C, et al. Preterm birth and the metabolic syndrome in adult life: a systematic review and meta-analysis. Pediatrics 2013;131:e1240-63.

33 Catov JM, Lewis CE, Lee $\mathrm{M}$, et al. Preterm birth and future maternal blood pressure, inflammation, and intimal-medial thickness: the CARDIA study. Hypertension 2013:61:641-6.

34 Sunehag AL, Haymond MW. Glucose extremes in newborn infants. Clin Perinatol 2002;29:245-60.

35 Cowett RM, Farrag HM. Selected principles of perinatal-neonatal glucose metabolism. Semin Neonatol 2004;9:37-47.

36 Hawdon JM, Ward Platt MP, Aynsley-Green A. Patterns of metabolic adaptation for preterm and term infants in the first neonatal week. Arch Dis Child 1992;67(4 Spec No):357-65.

37 Garg M, Devaskar SU. Glucose metabolism in the late preterm infant. Clin Perinatol 2006;33:853-70; abstract ix-x.

38 Wackernagel $\mathrm{D}$, Dube $\mathrm{M}$, Blennow $\mathrm{M}$, et al. Continuous glucose monitoring in term and near-term infants at risk of hypoglycaemia —a pilot study. Arch Dis Child 2012;97:A400. 


\section{Clinically stable very low birthweight infants are at risk for recurrent tissue glucose fluctuations even after fully established enteral nutrition}

E Mola-Schenzle, A Staffler, M Klemme, F Pellegrini, G Molinaro, K G Parhofer, H Messner, A Schulze and A W Flemmer

Arch Dis Child Fetal Neonatal Ed 2015 100: F126-F131 originally published online November 7, 2014 doi: 10.1136/archdischild-2014-306168

Updated information and services can be found at: http://fn.bmj.com/content/100/2/F126

\section{These include:}

References This article cites 38 articles, 20 of which you can access for free at: http://fn.bmj.com/content/100/2/F126\#BIBL

Email alerting Receive free email alerts when new articles cite this article. Sign up in the service box at the top right corner of the online article.

Topic Articles on similar topics can be found in the following collections Collections

Childhood nutrition (297)

Childhood nutrition (paediatrics) (125)

Child health (1515)

Infant health (857)

Infant nutrition (including breastfeeding) (241)

Neonatal and paediatric intensive care (341)

Neonatal health (928)

\section{Notes}

To request permissions go to:

http://group.bmj.com/group/rights-licensing/permissions

To order reprints go to:

http://journals.bmj.com/cgi/reprintform

To subscribe to BMJ go to:

http://group.bmj.com/subscribe/ 